\title{
Tendência do estado nutricional da população idosa brasileira de 1989 a 2009
}

\author{
Mariana Fraga Oliveira, Mariana Barros Sucupira Contino, Luiz Antonio dos Anjos
}

\begin{abstract}
Resumo
O declínio das taxas de fecundidade e mortalidade vem aumentando progressivamente a proporção de idosos no Brasil, demonstrando a necessidade de se melhorar o conhecimento a respeito desta população. Estudos populacionais indicam que o estado nutricional (EN) da população jovem e adulta brasileira vem se modificando ao longo dos anos para um quadro de redução da desnutrição e aumento do sobrepeso/obesidade. O presente estudo tem como objetivo avaliar o EN da população idosa brasileira, com base na Pesquisa Nacional de Saúde e Nutrição (PNSN) realizada em 1989 e na Pesquisa de Orçamento Familiar (POF) realizada em 2008-2009. Os dados da POF pertinentes à presente análise (idade, sexo, macrorregião, renda, habitação, massa corporal e estatura) foram obtidos dos microdados disponíveis no site do IBGE. Para que fosse possível a comparação entre os dados das duas pesquisas, utilizou-se os métodos sobre avaliação realizada nos dados da PNSN por Tavares \& Anjos (1999), de onde se obteve os resultados da PNSN. O EN foi estabelecido pelo Índice de Massa Corporal, calculado como massa corporal dividida pelo quadrado da estatura, seguindo os pontos de corte da OMS (WHO, 1995). A idade foi estratificada em faixas de 5 anos a partir dos 60 até os 80 anos, sendo agrupadas numa única faixa após esta idade. Os dados foram processados no SAS, considerando a amostragem complexa das pesquisas com o uso dos respectivos pesos amostrais calibrados para representar a população brasileira. Na PNSN foram 4277 idosos com dados válidos que representavam 10229403 indivíduos. Do total, 47,4\% eram homens. Na POF foram analisados dados de 20099 idosos, representando 21341727 indivíduos, sendo 44,5\% homens. Havia mais mulheres em todas as faixas etárias e mais da metade da população estudada se concentrou na faixa de 60-69,9 anos em ambas as pesquisas. Em ambas as pesquisas observou-se que o percentual de sobrepeso Grau II e III foi maior entre as mulheres. A prevalência de magreza foi maior na PNSN em todas as faixas etárias, ao contrário da prevalência de sobrepeso, que foi maior na POF. Quando analisada por macrorregião, a prevalência de sobrepeso foi maior no Sul, Sudeste e Centro-Oeste em relação ao Norte e Nordeste, ao contrário da magreza, que foi maior os dois últimos. A área rural se destacou nas prevalências de magreza e adequação. $\mathrm{O}$ percentual de magreza foi inversamente proporcional à renda média domiciliar per capita e às condições de moradia em ambas as pesquisas. $\mathrm{O}$ presente trabalho pôde confirmar a transição nutricional no Brasil entre os idosos. Os dados da PNSN, de 1989, apresentam uma população idosa cujo estado nutricional é majoritariamente adequado, com prevalências de magreza e sobrepeso pouco preocupantes. Em contrapartida, os dados da POF de 2008-09 revelaram uma população com tendência ao sobrepeso e menores prevalências de magreza. Este achado se assemelha ao achado para a população brasileira mais jovem e requer planejamento do setor de saúde para enfrentá-lo adequadamente.
\end{abstract}

Descritores: Saúde Pública; Idoso; Estado Nutricional. 